\title{
Evaluating Government Regulations
}

\section{Bryce Wilkinson}

$\mathrm{G}$ overnments commonly acknowledge the need to improve the quality of government regulation, or to reduce undue regulatory burdens. This raises the question of what criteria should be used to evaluate the quality of a regulation.

Economists and lawyers - constitutional lawyers or legal draughtsmen tend to use different, but arguably largely complementary, criteria to evaluate regulations. In New Zealand, at least, the two approaches have been evolving independently. The lead economic ministries have supported the Australian approach of a regulatory impact statement (RIS) requirement centred on costbenefit analysis (CBA). This approach assumes, inter alia, that a recognisable legal system is already in place; otherwise a benefit could not be distinguished from a cost.

In contrast, a legal and constitutional approach to testing a regulation is directly concerned with its conformity with the requirements of a recognisable legal system and with legal and constitutional principles that relate to process and content. In New Zealand, Cabinet has made an ad hoc advisory committee of independent legal experts, the Legislation Advisory Committee (LAC), responsible for identifying such principles (see below). Legal arrangements in Australia differ markedly in some respects because of its federal structure and written constitution. This article focuses on the New Zealand situation.

In New Zealand, the Cabinet Manual requires regulatory proposals taken to Cabinet to be tested against both the RIS requirement and the tests identified by the LAC. The next two sections of this paper summarise these approaches. The first also argues that CBA cannot satisfy current expectations that it play a central role in improving the quality of regulations.

A third section motivates and outlines a synthesis of these two approaches to evaluating a regulation that is proposed and justified in much more detail in Constraining Government Regulation: A Discussion Document, (CGR, 2001). The writer was the principal author of this discussion document. He was assisted by his colleague Sue Begg, University of Chicago law professor Richard Epstein and George Mason University economics professor Tyler Cowen.

CBA does not play a central role in the proposed schema for evaluating the quality of a regulation. The proposed schema instead emphasises the importance of a principled approach to the issues of compensation and consent when the State uses its power of eminent domain to take some citizen's rights in private property for the benefit of others, or to reallocate uses of property held in common. The

Dr Wilkinson is a Director of Capital Economics Limited, an economic consulting firm in Wellington, New Zealand. 
issues of compensation and consent are fundamental to a system of voluntary exchange and to constitutional government.

The final section makes some concluding observations on the principles and tests proposed for regulatory analysis.

\section{Regulatory Reform Based on Comparing Predicted Outcomes}

In recent years the Organisation for Economic Cooperation and Development (OECD) has advocated the use of regulatory impact analysis (RIA) in order to reduce regulatory excesses. RIA aims to improve transparency and public consultation by requiring assessments of important impacts, fiscal costs, compliance costs, or formal CBA.

In March 1995, RIA was a key component of the OECD Council's recommended ten-point checklist approach to regulatory reform. In 1997 ministers of member countries endorsed an OECD report on regulatory reform recommending that governments should integrate RIA into the development, review and reform of regulations.

While CBA is not necessarily at the centre of a RIA, it is at the centre of a widely adopted version of this approach - the requirement for new regulations to be accompanied by a Regulatory Impact Statement (RIS). Australian was ahead of most countries in adopting a RIS requirement in 1985 for all Commonwealth Cabinet proposals affecting business.

By 2000, according to Australia's Productivity Commission (2002:37), 20 of the 28 OECD countries used some form of a RIS requirement. It reported that 14 of those countries employed broadly similar requirements to those in Australia. These included Canada, New Zealand, the United Kingdom and the United States. A further six countries used RISs for some regulations or in some circumstances.

In New Zealand the RIS requirement is set out in sections 3.23-3.38 of the Cabinet Office's Step by Step Guide. The stated objective is to 'improve the quality of regulation making and to ensure that regulatory proposals are costeffective and justified'. Sections 5.28 and 5.52 of the Cabinet Manual provide that all policy proposals submitted to Cabinet, which result in government bills or statutory regulations, must be accompanied by a RIS, unless an exemption applies.

Each RIS must contain statements of:

- the nature and magnitude of the problem and the need for government action;

- $\quad$ the public policy objective(s);

- feasible options (regulatory and non-regulatory) that may constitute a viable means for achieving desired objective(s);

- the net benefit of the proposal, including the total regulatory costs (administrative, compliance, and economic costs) and benefits (including non-quantifiable benefits) of the proposal, and other feasible options; and

- the consultative program undertaken. 
How effective are such requirements? Competent analysis can be difficult, costly, and inconclusive. The OECD (1997:20) reports that:

... there is a broad consensus that, properly done, RIAs can be effective in helping to produce the most effective, least cost instruments, though they require additional resources. An evaluation of 15 RIAs in the United States found that they cost about $\$ 10$ million to conduct but resulted in revisions to regulations with estimated net benefits of about $\$ 10$ billion, or a benefit to cost ratio of about 1,000 to 1 . The Canadian Business Impact Test has been judged effective particularly in assessing SME (small enterprises) impacts. But RIA is very hard to do properly. More work is needed to strengthen the methods, procedures and practice of RIA and to strengthen regulatory management to support its timely and effective use.

Reflecting the conceptual difficulties with CBA and the problems of costs and incentives, it should be no surprise that the OECD also reports 'massive noncompliance and quality problems' and that in most countries 'it is still a marginal influence on regulatory decision-making'.

Even in the United States, two decades of investment in RIA has not produced an encouraging result. Robert Hahn et al (2000) found that:

This study provides the most comprehensive evaluation of the quality of recent economic analyses that agencies conduct before finalizing major regulations. We construct a new dataset that includes analyses of forty-eight major health, safety, and environmental regulations from mid-1996 to mid-1999. This dataset provides detailed information on a variety of issues, including an agency's treatment of benefits, costs, net benefits, discounting, and uncertainty. We use this dataset to assess the quality of recent economic analyses and to determine the extent to which they are consistent with President Clinton's Executive Order 12866 and the benefit-cost guidelines issued by the Office of Management and Budget (OMB). We find that economic analyses prepared by regulatory agencies typically do not provide enough information to make decisions that will maximize the efficiency or effectiveness of a rule. Agencies quantified net benefits for only 29 per cent of the rules. Agencies failed to discuss alternatives in 27 per cent of the rules and quantified costs and benefits of alternatives in only 31 percent of the rules. Our findings strongly suggest that agencies generally failed to comply with the executive order and adhere to the OMB guidelines.

In Australia, achieving formal compliance seems to be a diminishing problem. The Productivity Commission (2002:8) reports an extremely high rate of compliance in recent years. For example, for the 2001-02 year it reported that 130 
RISs out of a required total of 145 were prepared at the executive's decisionmaking stage, of which 128 were 'adequate'. Compliance was even greater at the tabling stage. It observed that compliance was noticeably lower (at 70 per cent) for proposals having a significant impact. At the state level, the rate of compliance with the separate RIS requirements of the Council of Australian Governments was also very high at 96 per cent.

While it is not clear how the Productivity Commission's standard for adequacy compares with that used by Hahn et al, its report enhances the expectation that materially improved outcomes should result from the Australian approach by asserting (2002:50) that the Commonwealth RIS requirements have 'in many respects led best practice internationally' and have a high degree of consistency with the OECD's best practice guidelines for RIAs. The report also makes a strong claim that materially improved outcomes have resulted. The first 'key point' it makes in its overview (2002:xii) is that the reform of regulations 'has generated significant gains for Australia'.

Unfortunately, the evidence the Productivity Commission's report presents in support of the claim of significant gains is disappointing. The overview focuses on improved compliance and does not establish that this has improved the quality of the regulations being passed. When the report compares regulations in Australia with other countries it focuses on business compliance costs. Even here it finds (2002:xviii and 44) only that the burden in Australia is around 2.9 per cent of gross domestic product. It puts this at around the OECD average, and higher than in New Zealand.

There are no grounds for surmising that New Zealand's lower burden results from its own RIS requirement. Tasman Economics (2001) reviewed the effectiveness of the RIS regime in New Zealand for the Ministry of Economic Development and the Treasury. The review found that 'many regulatory impact statements were far too brief, given the importance and complexity of the issues being addressed and were of poor quality'. It did not say whether any were satisfactory overall. It made a number of recommendations for improving the design of the regime and compliance with its requirements.

More recent examples of RISs in New Zealand indicate that this requirement lacks teeth (Wilkinson, 2002). Without a strong government commitment to ensuring high-quality RISs, government departments may rationally make little effort to undertake a competent analysis.

Nor may judicial review adequately guard against bad analysis. Economist William Niskanen (1997) has drawn attention to the reluctance of the courts to accept the role of evaluating scientific and economic studies. Epstein (1995:97 and 103) has independently argued in another context that it is desirable that judges focus on applying the law — determining if an action was legal — rather than allowing their decisions to be affected by explicit references to CBA.

In any case, techniques such as CBA cannot claim a mantle of pure scientific objectivity and efficiency. CBA is essentially a central planning tool, albeit one that is seriously limited in its ability to handle distributional issues. It presumes that costs, benefits and discount rates can be objectively determined and gathered 
together in one place for the benefit of a government decision-maker with the precision necessary for taking a useful decision. However, opportunity costs are subjective and the costs of undertaking a competent CBA are so high as to ensure that in many cases decisions will be made on the basis of seriously inadequate information. Furthermore, CBA does not align the incentives of government decision-makers or analysts with the national interest. The problems of information and incentives create the potential for material bias. Viscusi et al report (1998:326) that a large amount of evidence rejects the public interest theory that regulation occurs where there is the potential for a net social welfare gain.

A competent CBA may usefully inform decision makers, but it cannot eliminate the need for significant and controversial value judgments in particular cases. Reflecting on the well-known weaknesses of CBA, Niskanen concluded that the net benefit standard does not provide a sufficient basis for the redistribution of income, the taking of private property for a public benefit, or for restricting the activities of individuals and firms that bear the full cost of their actions.

Boston University law professor Randy Barnett (1998:322-325) makes a more general argument. It is that the problems of information and incentives that make CBAs problematic affect public policy analysis generally. He concludes that law-making should be informed by considerations of justice rather than solely by public policy analysis.

\section{Regulatory Reform Based on Legal Guidelines}

Legal scholars and the professional lawyers that draft legislation examine the quality of its structure. Yale law professor Lon Fuller (1969) identified a number of tests for the very existence of a recognisable legal system - Will people be able to understand it? Does it actually give effect to the intended policy? Is it necessary, or does it replace existing common law by something less satisfactory? Is it constitutional? Is it internally consistent? Does it conflict with other laws? Does it require conduct beyond the powers of those affected, as in the case of retroactive legislation?

Legal experts, such as former academic and justice minister Sir Geoffrey Palmer and New Zealand's Law Commission (1995), have stated in very strong terms that legislation in New Zealand commonly fails to pass basic legal tests. In February 1986, the then Geoffrey Palmer, as Minister of Justice, established the LAC to help improve the quality of legislation in New Zealand. One of its two main functions is to produce guidelines that are fundamental for developing legislation, such as proper processes and basic legal principles. These are known as the LAC Guidelines: Guidelines on Process and Content of Legislation (LAC Guidelines). Its second main function is to advise the relevant minister or the Cabinet Legislation Committee on these issues in relation to particular legislation, when requested to do so.

The Ministry of Justice services the LAC. The LAC reports to the Minister of Justice and the Legislative Committee of Cabinet on the public law aspects of 
legislative proposals. Its first guidelines were prepared in 1987 and the latest edition was released in 2001. They are designed to set out central aspects of the law-making process and to specify elements of the content of legislation that should always be addressed.

The 2001 LAC Guidelines provide the following checklist for a regulation as it affects basic principles of New Zealand's legal and constitutional system:

1. Does the legislation comply with fundamental common law principles?

2. Have vested rights been altered? If so, is that essential? If so, have compensation mechanisms been included?

3. Have pre-existing legal situations been affected, particularly by retroactivity? If so, is that essential? What mechanisms have been adopted to deal with them?

4. Does the legislation enable the levying of money? If so, is the levy a tax imposed other than by Parliament?

Such tests potentially constrain the content of legislation, independently of the economist's calculations of likely future impacts, costs or benefits. A such they are different in kind from restrictions based on CBA.

The LAC Guidelines state that the common law is organised around a respect for individual dignity and individual possession of property, and the supremacy of Parliament as a source of law. However, where there is doubt as to exactly how a particular provision of a statute will mesh in with, or prevail over, the common law, the courts may reach a decision by giving weight to common law presumptions based on concern for the preservation of individual rights. Of particular interest here is the following statement in the LAC Guidelines:

The basic common law perspective of the courts is that a person's liberty and property will only be taken away or confined after due process of the law, which processes are designed to ensure that no one is deprived of individual liberty unless a case is proven against that person by fair procedures. [Emphasis in original.]

The same chapter of the LAC Guidelines cites approvingly Lord Hoffman's dictum in 1999 that while parliaments can legislate contrary to fundamental principles of human rights, fundamental rights cannot be overridden by general or ambiguous words. The courts may therefore presume that even general words do not remove the basic rights of the individual.

In contrast to the economic approach to evaluating regulations on the basis of predicted costs and benefits, the LAC Guidelines put common law principles on centre stage. However, this approach is not without difficulty. The $L A C$ Guidelines enumerate an incomplete list of 18 'fundamental common law principles'. The list seems somewhat idiosyncratic. For example, it omits freedom of association, yet includes such novel rights as freedom from discrimination [by private persons] and conformity with the Treaty of Waitangi. 
Of greatest interest to the topic of this paper is the unqualified statement that the principle that property will not be expropriated without full compensation is a fundamental common law right. The LAC Guidelines make no attempt to limit the definition of property to real estate. By way of elaboration, they state:

If property is involved and if what is proposed is a taking, consideration will need to be given as to whether or not compensation should be provided. In these circumstances, if compensation is not to be paid the legislation should make quite clear this presumption.

They state that ' $[t]$ he development of this presumption reflects the fact that "the protection of property is generally regarded as one of the fundamental values of a liberal society". (Cross, p 179)'.

The Public Works Act 1981 fully conforms to the principle that compensation be paid in relation to land (see below). However, other legislation directly contradicts it. For example, section 85 of the Resource Management Act 1991 commences: 'Compensation not payable in respect of controls on land' [sic].

Although the Cabinet Manual requires new legislation to be tested for its conformity with the LAC Guidelines, the author is not away of any evidence that they are having a material effect to date on the quality of new legislation. Evidence of the ongoing expropriation of property rights without due compensation is easy to find. For example, the legislation ratifying the Kyoto Protocol expropriates carbon sink credits. This has angered forestry plantation owners.

\section{A 'Law and Economics' Synthesis}

The formal 'Arrow-Debreu' neo-classical economics analysed production and exchange equilibria assuming that a 'given' system of individual property rights and freedom of contract was in place. CBA similarly assumes a given legal system of legitimate individual rights, otherwise it would not be possible to distinguish an avoided harm from a benefit. A regulation that takes only some of the legal rights of its victims could be said to benefit them because it does not take all of their rights.

Tom Bethell (1998) has documented the failure of economists for two centuries to analyse the legal institutions that underlay their analysis of production and exchange. He suggests that the classical economists failed to do so because the sanctity of private property rights was so entrenched that a defence would be superfluous. Nor did their successors adequately fill the breach when Marxist and other attacks succeeded in bringing the institution of private property into intellectual disrepute. Particularly in the environmental area, it seems common today for those supporting a restriction on land use to deny the legitimacy of the existing owner's 'development rights'.

Bethell has also documented the growing appreciation amongst some academic economists in recent decades, and in the last decade in international 
organisations such as the World Bank, of the importance for prosperity of a legal system that facilitates production and exchange, and human welfare more generally. Economists such as Peru's Hernando De Soto have emphasised the relationship between chronic poverty and the absence of a legal framework that gives legitimacy to established (customary) rights.

The set of laws and regulations that is most conducive to economic efficiency or prosperity is not necessarily the same as the set that best secures individual liberty, natural rights, or diverse concepts of 'justice'. There is ample scope for disagreement, for example, as to whether the common law is, or should be, efficient. Nevertheless, there is also scope for much common ground between public policy lawyers and economists concerning the necessity for a sound legal system and the important characteristics of such a system.

Both a legal and an economic analysis may concur that a prime role of the state is to uphold the law so that individuals are secure in their rights to person and property. Many may also agree that in certain situations the state may validly take these rights in the public interest. (In the United States, the power of the state to take private property in the public interest is known as the power of eminent domain.)

There is an obvious tension between these two roles for the state. Frederic Bastiat (1850:14) pinpointed it vividly as follows:

As long as it is admitted that the law may be diverted from its true purpose - that it may violate property instead of protecting it then everyone will want to participate in making the law, either to protect himself against plunder or to use it for plunder.

To guard against this danger, State takings must be limited and principled if the State is to achieve its prime purpose. The search for better laws and regulations is in good part a search for well-designed constraints on State takings.

One important constraint is to require the state to conform to due process. Ideally, independent courts determine whether due process has been followed and the individual's right of judicial review is protected. The due process clauses in the Fifth and Fourteenth Amendments to the United States constitution state that: '... nor shall any person ... be deprived of ... property without due process of the law'.

A second important constraint is the requirement that compensation be paid where the state does take private property in the national interest. The US Fifth Amendment states: '.. nor shall private property be taken without due compensation'.

In the common law countries, the importance of limiting the use of the power of eminent domain is acknowledged in the legislation that providing for the taking of public land for public works. For example, key constraints in the initial Public Works Act 1981 legislation in New Zealand included the provisions that: 
- there was only to be recourse to compulsion if voluntary agreement was not obtained following due processes;

- required that the taking be 'necessary' for an 'essential' public interest;

- ensured that full compensation was paid to property owners; and

- incorporated the principle that those who benefit should fund the compensation (under the 'betterment' principle, a landowner might receive in cash less than full compensation for land taken for a public work if the same work increased the value of the landowner's remaining land).

Economists might interpret the requirement to pay compensation as going some way to mimic the feature under a system of voluntary exchange where a supplier of a good or service relinquishes property rights in the same to the buyer in return for a consideration of at least equal value. Indeed, the features of mutual benefit and the absence of coercion that underlie a system of voluntary exchange are the hallmarks of civil society.

In a public good context, the requirement that the State should pay compensation for the taking of rights in private property can be interpreted as an imperfect safeguard against the system of forced and predatory exchanges of the type feared by Bastiat. The safeguard is particularly imperfect to the degree that any compensation is funded by taxpayers who are not representative of the group that actually stands to benefit from the expropriation of property. Taxpayer funding without the consent of taxpayers or their representatives puts taxpayers at risk.

By the same token, a decision to take private property without ensuring full compensation is in general a decision to tax the owners of that property. Again such taxes should conform to sound tax principles, both as a matter of justice and economic efficiency. Any taxes used to fund public goods should, in principle, raise the welfare of all citizens. If so, they should be able to command the general consent of those who pay the taxes.

Indeed, the events leading to the American declaration of independence in 1776 demonstrated the power of the fundamental constitutional principle that taxes should not be levied except with the consent of those being taxed, or their representatives. This principle raises the issue of who can validly claim to be the representatives of those being taxed. The constitutional presumption that parliament should not delegate the power to tax indicates acceptance of the view that parliament is more representative of taxpayers' interests than is executive government. Even so, parliamentarians face an obvious conflict of representation when it comes to taxing one group of voters for the benefit of others. (Clearly, an uncompensated taking may be a highly predatory tax.) This difficulty motivates consideration of other constraints such as a bicameral system and greater recourse to referenda. Space does not permit their discussion here.

These principles - the desirability of limiting government takings under the power of eminent domain to important matters of public interest and the need to conform to sound principles for taxation and compensation - provide a different approach to testing the quality of a law or regulation from that adopted under the 
above RIA or RIS approaches. In particular, they do not treat subjective future costs and benefits as technocratic variables that can be objectively estimated by central planners or economists who are not personally incurring the costs or the benefits.

CGA used the above principles of consent and compensation, and the presumption in favour of fundamental common law principles, to propose the following five principles for testing a law or regulation:

(a) Laws and regulations should enhance security from legal harms in person, liberty, contract and property;

(b) Laws and regulations should preserve common law causes for action that have prevailed for centuries against harms caused by strangers. They should not introduce novel or expanded concepts of legal harms and expansive definitions of an interested party, or remove legal harms whose utility has survived the test of centuries;

(c) Laws and regulations should preserve or enlarge the scope for individual action, and thereby for voluntary cooperative action. They should enhance freedom of contract and exchange;

(d) Laws and regulations that reallocate legal rights by force must be justified on the basis that they are necessary for the achievement of an essential public interest. In addition, such laws and regulations must:

(i) not delegate from parliament the power to levy taxes;

(ii) preserve the principle that taxes should be levied in the public interest only with the general consent of those who are liable to pay those taxes;

(iii) preserve the principle of full compensation for those whose legal rights under common law are taken or impaired in the public interest;

(iv) preserve the principle that such compensation should be funded by the new legal owners or, if the government assumes the taken rights, by those in whose interests the taking was justified;

(v) preserve the principle that surpluses arising from the exercise of the power of eminent domain are divided amongst those who are parties to the exchange in proportions that reflect the size of their original contributions;

(vi) require evidence of consent under principle d(ii) from those who are effectively being taxed in cases that are an exception to principles $\mathrm{d}($ iii) or d(v);

(e) Laws and regulations should otherwise preserve or enhance the rule of law. In particular, they should:

(i) not take retrospective effect;

(ii) avoid imprecise terms and complexities that materially undermine the ability of citizens to understand the law and therefore to comply with it;

(iii) increase certainty as to what actions are legal; 
(iv) ensure that the constraint of judicial review applies to the exercise of delegated administrative and executive powers in relation to the discretion to set user charges, attach conditions to permits or consents, or change the use of assets within the public sector;

(v) uphold the principle that all are subject to the law - including the government and its agencies; and

(vi) uphold the principle of equality under the law. Laws should be general and abstract, not mentioning specific categories of persons, gender, race, creed or religion, time or place.

Principle (a) provides for the use of police power. It allows laws and regulations that assist the state to enforce existing legal rights better. Law-abiding people should be secure in their persons, liberty and possessions.

Principle (b) is designed to test for stability in laws whose enduring value has been proven through the course of time. This is best interpreted as a consequentialist position, although such laws are likely to get the status of 'natural' laws or rights over the centuries.

Principle (c) aims to protect the domain for voluntary action from government encroachment by imposing a burden of proof on the latter. This guards against excessive regulations that stem from factional pressures, excessive paternalism, and grandiose presumptions about the ability of those in government to command the information needed to determine what outcomes best serve the interests of diverse individuals.

Principle (d) allows for the principled use of the power of eminent domain, including the power to tax in cases of necessity for an essential public interest (see below).

Principle (e) incorporates other elements of the rule of law. Subsection (e)(v) provides for judicial review.

The thrust of these principles is to allow laws and regulations that are consistent with them to escape the detailed scrutiny that would then be applied to other laws and regulations.

The 2001 LAC Guidelines and the above principles have much in common. Both acknowledge the importance of preserving fundamental common law principles, although the language differs. Both emphasise the importance of individual security in person and property and the concomitant importance of paying compensation when private property is taken in the public interest

However, there are also some noteworthy differences. The LAC Guidelines list freedom from discrimination and compliance with the Treaty of Waitangi as fundamental common law principles. They do not include freedom of association and the principle of consent to taxation.

$C G R$ converts the above five principles into the following sequence of tests that could be used to screen laws and regulations. 


\section{Exhibit: Schema for Using the Proposed Principles to Test a Law or Regulation}

Test 1 Does it increase individual freedom of action, contract and exchange?<smiles>[C-]1CCCC1</smiles><smiles>C1CCCC1</smiles><smiles>[Y]O[Ga]C1=C=C1</smiles>

Test 2 Does it preserve venerable common law causes of action against harm or remove novel or expanded definitions of legal harms?<smiles>C1CCC1</smiles><smiles>C1CCC1</smiles><smiles>C=CC(=O)O</smiles>

Test 3 Does it preserve existing legal rights and other elements of the rule of law?<smiles>C1CCC1</smiles><smiles>C1CCC1</smiles><smiles>C=CC=CC</smiles>

This law or regulation complies with principles (b), (c) and (e).

Test 4 Is each and every element that violates Tests 1,2 or 3 necessary in order to obtain a benefit that is essential to the well-being of the public at large?<smiles>C1CCC1</smiles><smiles>C1CCC1</smiles>

$\Longrightarrow$ Amend it accordingly.

Test 5 Does the proposed law or regulation preserve existing legal rights?<smiles>C1CC2CC1C2</smiles>

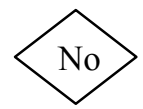

$\Longrightarrow$ Report to parliament on compensation and consent.

Test 6 Is it consistent with the proportionality principle for the distribution of surpluses?<smiles>C1CCC1</smiles>

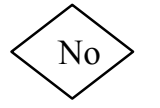

$\Longrightarrow$ Amend it accordingly.

Test 7 Does it effectively tie a tax to a permit without explicit parliamentary scrutiny?<smiles>C1CCC1</smiles><smiles>[C-]1CCC2CCC12</smiles>

$\Longrightarrow$ Amend it accordingly.

END TESTS 
Tests 1, 2 and 3 incorporate principles (c), (b) and (e) respectively. A regulation that passes these three tests passes all the tests. It will be a regulation that does not use the power of eminent domain to reallocate 'venerable' common law rights. These are no doubt analogous to the concept of fundamental common law principles in the $L A C$ Guidelines, except that the test of what is venerable is more clearly a consequentialist test.

Deregulation - the removal of command and control regulations aimed at imposing outcomes rather than clarifying rights that can later be voluntarily reassigned - should pass these three tests. Taxes to fund state-provided public goods are likely to fail test 1 .

Laws and regulations based on the use of the power of eminent domain may fail those tests, particularly test 3 , for practical reasons. The scheme then screens these and other regulations for their compliance with tests 4 to 7 .

Test 4 incorporates principle (d). It screens regulations that fail one or other of the first three tests for their necessity in terms of an essential public interest. It allows tax-funded public goods where the tests of necessity and essentiality are satisfied.

Tests 3 and 4 would allow for a taxpayer-funded welfare safety net where tests of the consent of taxpayers or their representatives and of necessity and essentiality were satisfied.

Test 5 aims to ensure that the issue of compensation is addressed by parliament. It also invokes the issue of consent.

Test 6 asks whether the regulation distributes any surpluses that arise from the exercise of the power of eminent domain in a non-proportional, exploitative, manner. It aims to ensure that the distribution of any surpluses is scrutinised.

Test 7 screens for the abuse of the power to attach conditions to the issuance of permits.

These tests could inform any thorough review of existing regulations. They could also be incorporated into any guidelines or processes put in place to guard against regulatory excesses in new laws or regulations.

How effective might these tests be? They are less likely to be effective the greater the degree to which the problem of too many bad laws or regulations stems from voter failure rather than from political failure. In the absence of any clear agreement in the community about the need for constitutional constraint and principled government takings, the problem of voter failure is particularly intractable. Obvious weaknesses in the above proposals arise in practice from the need to secure meaningfully constraining definitions for terms such as 'venerable', 'essential', 'necessary' and 'public interest'. Formally, for example, necessary as a mathematical term means 'otherwise impossible' as in ' $\mathrm{A}$ is a necessary condition for B'. However, there is an obvious risk that popular governments and compliant courts could soon define 'necessary' to mean 'convenient' (to the ruling elite).

Similarly, the term 'essential' public interest is intended to impose a high threshold in the form of requiring that the power of eminent domain only be used 
sparingly where it is necessary to do so in order to achieve a major gain in community welfare. Economists might measure this by the sum of producer and consumer surplus. However, again, governments or the courts could easily emasculate such a constraint if public or elite opinion was sufficiently quiescent. For example, in New Zealand the test of essentiality in the Public Works Act 1981 was repealed in 1987, ostensibly on the grounds that it created too many definitional problems. However, it is not obvious that the new criteria of 'fair, sound and reasonably necessary' are any better in this respect. Section 7.5 in CGR discusses many of these complexities in greater detail.

\section{Concluding Comments}

Civil society depends on securing principled, constitutional government - as distinct from arbitrary, unprincipled, or despotic government. In conjunction with high levels of economic freedom this should also facilitate wealth creation.

The principles and tests proposed here and in $C G R$ are designed to complement the RIS tests based on CBA by adding a law and economics perspective. The proposed synthesis aims to reduce reliance on CBA assessments by putting greater reliance on evidence of the participants' assessments of the costs and benefits.

The proposed principles and tests accept that regulations that take private property rights by force may be sometimes desirable in order to overcome barriers to mutually beneficial exchanges. However, they aim to preserve the principle that such exchanges, if welfare enhancing, should have the potential to make all parties to the forced transactions better off (ex ante) than if the regulation were not passed. Even where practicalities prevent such a pure result, compliance with due process based on the principles of constitutional restraint, consent to taxes, mutual benefit, and respect for the legitimate rights of others should both promote civil society and preserve incentives to create wealth by guarding against unprincipled and predatory takings.

The proposals in $C G R$ are intended to promote public debate about the need for a deeper and more far-reaching approach to a widely acknowledged problem. The tests are proposed as a basis for discussion and refinement. They are not a panacea for the problem of an excess of bad regulation. Nor is there a program for putting them in place. To put them in place would require real political will to improve the quality of regulations by constraining future governments to take a more principled approach. Such a will is likely to emerge in time if current remedies prove to be ineffectual and the problems persist.

\section{References}

Barnett, R. (1998), The Structure of Liberty: Justice and the Rule of Law, Clarendon Press, Oxford and New York.

Bastiat, F. (1850), The Law, translated by Dean Russell, Foundation for Economic Education, Irvington-on-Hudson, New York, 1998. 
Bethell, T. (1998), The Noblest Triumph: Property and Prosperity through the Ages, St Martin's Press, New York.

Epstein, R. (1995), Simple Rules for a Complex World, Harvard University Press, Cambridge, Massachusetts.

Fuller, L. (1969), The Morality of Law, Yale University Press, New Haven.

Hahn, R., J. Burnett, I. Yee-Ho Chan, E. Mader and P. Moyle (2000), 'Assessing the Quality of Regulatory Impact Analyses’, Brookings, Working Paper 00-01, January.

Legislation Advisory Committee (2001), 'Legislation Advisory Committee Guidelines', Guidelines on Process and Content of Legislation, May, http://www.justice.govt.nz/lac/index.html.

New Zealand Business Roundtable (2001), 'Constraining Government Regulation: A Discussion Document'.

New Zealand Law Commission (1995), Annual Report 1995, Report 33, Wellington.

Niskanen, W. (1997), 'Regulatory Reform: No Silver Bullet', Cato Handbook for Congress, Cato Institute, 26 February.

Organisation for Economic Co-operation and Development (1997), Regulatory Impact Analysis: Best Practices in OECD Countries, OECD, Paris.

Productivity Commission (2002), Regulation and its Review 2001-02, Annual Report Series, Productivity Commission, Canberra.

Tasman Economics (2001), 'Regulatory Impact Statements', mimeograph, March.

Viscusi, W, J. Vernon, and J. Harrington Jr (1995), Economics of Regulation and Antitrust, The MIT Press, Cambridge, Massachusetts, $2^{\text {nd }}$ edition.

Wilkinson, B. D. (2002), 'The Problem of Inadequate Regulatory Impact Statements', IPS Policy Newsletter, No. 70:13-18, August, Institute of Policy Studies, Victoria University of Wellington.

The author would like to thank Roger Kerr and two anonymous referees for their comments. 